\title{
Risk Factors and Clinical Outcome in Hemorrhagic Intracranial Dural Arteriovenous Fistulas After Endovascular Treatment
}

\author{
Chih-Cheng Wan \\ Fu Jen Catholic University \\ Chung-Wei Lee \\ National Taiwan University Hospital \\ Yen-Heng Lin \\ National Taiwan University Hospital \\ Hon-Man Liu ( $\square$ inr.liu@gmail.com ) \\ Fu Jen Catholic University
}

\section{Research Article}

Keywords: dural arteriovenous fistula (DAVF), hemorrhagic, endovascular treatment, clinical outcome, intracranial hemorrhage

Posted Date: December 16th, 2021

DOI: https://doi.org/10.21203/rs.3.rs-1138317/v1

License: (9) (1) This work is licensed under a Creative Commons Attribution 4.0 International License. Read Full License 


\section{Abstract}

Purpose The purpose of this study was to analyze the risk factors of hemorrhage in DAVFs and the factors that influence the clinical outcome of hemorrhagic intracranial DAVFs after endovascular treatment.

Methods We reviewed the records of patients with hemorrhagic intracranial DAVFs who received endovascular embolization from December 1996 to April 2015. We analyzed the risk factors of hemorrhage and emphasized the drainage pattern and the classification of drainage location. We also analyzed the factors that influence clinical outcomes such as the patient's age and the time interval between hemorrhage and treatment.

Results A total of 32 patients were included in this study. Twenty-seven (84.4\%) had engorged medullary veins (EMVs), and 24 (75\%) of the hemorrhagic DAVFs had dorsal epidural drainage. Twenty-five (78.1\%) had complete occlusion on post-procedural angiography. A significant difference $(p=0.0054)$ of the modified Rankin Scale after treatments between the groups who received treatment within or exceeding 14 days after diagnosis.

Conclusions Regional EMVs and dorsal epidural drainage patterns are risk factors in the prediction of hemorrhage in intracranial DAVFs. Patients who received early treatment within 14 days after hemorrhage could have a better clinical outcome.

\section{Introduction}

Nearly $20 \%$ of cases with dural arteriovenous fistula (DAVF) present with intracranial hemorrhage [1, 2], and venous drainage pattern is considered as the major risk factor especially those associated with cortical veins reflux (CVR) [2-8]. However, in one recent study, hemorrhage occurred in only 16 of 103 (8\%) DAVF patients with CVR [9]. The annual mortality rate for CVR had been reported as high as $10.4 \%$ with an annual risk of hemorrhage of $8.1 \%$ and of non-hemorrhagic neurological deficits of $6.9 \%$ [7]. These risks in combination give an annual event rate of $15 \%$ [4]. A re-hemorrhage rate of $35 \%$ has been quoted in the first 2 weeks following an initial bleed [6]. However, another study found that in patients of DAVF with CVR presenting with an intracranial hemorrhage, the annual risk for hemorrhage is approximately $7.4 \%$, and in those not presenting with a hemorrhage is approximately 1.5\% [10]. Another group found cranial DAVFs with asymptomatic CVR may have a less aggressive clinical course than those with symptomatic CVR, with annual event rates $1.4 \%$ versus 19.0\% [11]. In addition to CVR, engorged medullary veins (EMVs) and regional type EMVs [9, 12], and the locations of DAVFs [13] had been reported as risk factors of hemorrhagic presentation in DAVFs.

Reports on the outcome in patients with hemorrhagic intracranial DAVFs is limited. In a systematic review, the case mortality of hemorrhagic DAVF was 4.7\%, and poor outcome (modified Rankin scale; mRS $\geq 3$ ) was found in 8.3\% [14]. Reports about the outcome of hemorrhagic DAVFs after treatment are even rare. The purpose of this study was to analyze the risk factors of hemorrhage in DAVFs, the outcome of hemorrhagic DAVFs after endovascular treatment, and the factors which might influence the final outcomes.

\section{Results}

Among the 283 patients of DAVFs in the study period, we found a total of 32 patients (11.3\%) presenting with intracranial hemorrhage prior to the treatment. The mean age of these patients was 61.3 years old (31-81, 95\% confidence interval, 64.3 \pm 11.1$)$. Twenty-two are males (68.8\%). The clinical presenting symptoms and signs were: 22 (68.8\%) with headache, $12(37.5 \%)$ with deteriorated consciousness or coma, 7 (21.9\%) with focal neurologic deficit, 7 (21.9\%) with seizure, and 2 (6.3\%) with dementia. The Cognard classifications before treatments were: 1 with type IIA (3.0\%), 7 with type IIB (21.9\%), 2 with type III (6.3\%), and 22 with type IV (68.8\%). Regarding the types of intracranial hemorrhage, 6 (18.8\%) had subarachnoid hemorrhage (SAH) alone, one (3.1\%) had subdural hemorrhage (SDH) alone, 23 (71.9\%) had intracerebral hemorrhage $(\mathrm{ICH})$ alone, and $2(6.3 \%)$ had SAH with $\mathrm{ICH}$. The average interval between when the hemorrhage was found and treatment was 17.1 days (0 to 170). EMVs were presented in 27 cases (84.4\%), and 26 of them were regional types. According to Geibprasert et al.'s classification, 24 (75\%) of our hemorrhagic DAVFs had dorsal epidural drainage, 3 (9.4\%) had both ventral and dorsal epidural drainages, 2 (6.3\%) had lateral epidural drainage, 1 (3.1\%) had ventral epidural drainage, 1 (3.1\%) had both dorsal and lateral epidural drainages, and 1 (3.1\%) had both ventral and lateral epidural drainages. We used transvenous approaches in 18 patients (Fig. 1), transarterial in 13, and combined transarterial and transvenous approaches in 1 (Fig. 2). We solely used electrically detachable coils in transarterial or transvenous approaches in 19 cases (59.4\%), N-butyl cyanoacrylate (NBCA; Histacryl, Braun Melsungen, Germany) in 2 cases (6.3\%), Onyx (Medtronic, USA) in 3 cases (9.4\%), and particles in 1 case (3.1\%). Three cases (9.4\%) were treated by a combination of coils and NBCA, 2 cases (6.3\%) by coils and particles, 1 case (3.1\%) by NBCA and particles, and 1 case (3.1\%) by coils, NBCA, and particles. Twenty-five (78.1\%) had complete occlusion on immediate post-procedural angiography.

The final mean $m R S$ after treatments was 0.84 . Poor outcome (mRS $\geq 3$ ) was noted in five patients (15.6\%). Among them, one had a type III Cognard classification and four had type IV lesions. We subdivided the patients into groups above and below 65 years old, there were no

Page 2/9 
significant differences in the long-term outcome by $\mathrm{mRS}(\mathrm{p}=0.627)$ between these two groups. There was no significant difference in $\mathrm{mRS}$ $(p=0.810)$ between male and female patients, either. Regarding the timing of treatment, a significant difference was found in the mRS after treatments $(p=0.0054)$ between the groups treated within and for more than 14 days. But no significant difference in mRS in the following groups: $<7$ days vs. $7-14$ days $(p=0.316),<7$ days vs. $>14$ days $(p=0.057), 7-14$ days vs. $>14$ days $(p=0.053)$. However, we could infer that there are trends of patients with lower long-term mRS who received treatments less than 7 days and between 7 to 14 days than the patients treated more than 14 days to diagnosis. The mean mRS was 0.57 in the group $(n=22)$ receiving treatments within 14 days, and 1.8 in the group ( $n=10)$ diagnosed more than 14 days after the intracranial hemorrhage. This suggests a better outcome in the group of patients who had treatment within 14 days. No mortality after treatments and during the period of follow-up was noted, and no patients received additional surgical or stereotactic radiosurgery treatment in our study. In 25 patients (78.1\%), complete remission of lesions was obtained in clinical and imaging follow-up. Five patients' (15.6\%) lesions had been downgraded (to type 1 in four, type IIB in one). One patient (3.1\%) still had type IV lesion, and yet no clinical downhill or re-bleeding during the follow-up period in these cases. One patient (case2) failed endovascular treatment for his right foramen magnum DAVF due to vasospasm and thromboembolism complication in 2001 . He received open surgery and his mRS was 3 on 2-year follow-up.

Details about the demography, treatment, and outcome of these 32 patients was shown in Table 1. 
Table 1

Demography, treatment, and outcome of 32 patients of hemorrhagic intracranial dural arteriovenous fistulas

\begin{tabular}{|c|c|c|c|c|c|c|c|c|c|}
\hline & Age/sex & Symptoms/signs* & $\begin{array}{l}\text { Type of } \\
\text { hemorrhage }\end{array}$ & $\begin{array}{l}\text { Cognard } \\
\text { classification }\end{array}$ & $\begin{array}{l}\text { Engorged } \\
\text { medullary } \\
\text { veins ** }\end{array}$ & $\begin{array}{l}\text { Drainage } \\
\text { location }\end{array}$ & $\begin{array}{l}\text { Days } \\
\text { between } \\
\text { hemorrhage } \\
\text { and } \\
\text { treatment }\end{array}$ & $\begin{array}{l}\text { Obliteration } \\
\text { percentage }\end{array}$ & $\begin{array}{l}\text { mRS } \\
\text { in last } \\
\text { follow } \\
\text { up }\end{array}$ \\
\hline 1 & $36 /$ male & 1 & SAH & III & no & 2 & 17 & $100 \%$ & 0 \\
\hline 2 & $49 /$ male & 1,2 & $\mathrm{SAH}$ & IV & no & 3 & 24 & $0 \%$ & 3 \\
\hline 3 & $61 /$ male & $1,2,4$ & SAH & IV & extensive & 2 & 3 & $100 \%$ & 1 \\
\hline 4 & 70/male & 1,2 & SAH & IV & no & 3 & 18 & $100 \%$ & 4 \\
\hline 5 & $64 /$ male & 2,3 & $\mathrm{ICH}$ & IV & regional & 2 & 1 & $100 \%$ & 3 \\
\hline 6 & $61 /$ male & 1 & $\mathrm{ICH}$ & Illb & regional & 2,3 & 3 & $100 \%$ & 0 \\
\hline 7 & 71/female & 4 & $\mathrm{ICH}$ & IV & regional & 2 & 0 & $100 \%$ & 1 \\
\hline 8 & $59 /$ male & 1,2 & $\mathrm{ICH}$ & IV & regional & 2 & 37 & $100 \%$ & 3 \\
\hline 9 & $75 /$ male & 3 & $\mathrm{SAH}, \mathrm{ICH}$ & III & regional & 1,3 & 170 & $90 \%$ & 3 \\
\hline 10 & $63 /$ male & 1 & $\mathrm{SAH}, \mathrm{ICH}$ & IV & extensive & 2 & 4 & $95 \%$ & 0 \\
\hline 11 & $56 /$ male & 1,2 & SAH & IV & regional & 2 & 25 & $80 \%$ & 2 \\
\hline 12 & 72/female & 3 & $\mathrm{ICH}$ & IV & extensive & 1,2 & 0 & $100 \%$ & 1 \\
\hline 13 & $81 /$ female & 1 & $\mathrm{ICH}$ & IV & regional & 2 & 3 & $100 \%$ & 2 \\
\hline 14 & $63 /$ male & 1 & $\mathrm{ICH}$ & Ilb & regional & 2 & 1 & $100 \%$ & 0 \\
\hline 15 & $61 /$ male & 1,5 & $\mathrm{ICH}$ & IV & regional & 2 & 21 & $100 \%$ & 1 \\
\hline 16 & 66/female & 1 & $\mathrm{ICH}$ & $\mathrm{Ilb}$ & regional & 1,2 & 1 & $100 \%$ & 2 \\
\hline 17 & 77/female & 1 & $\mathrm{SDH}$ & IV & regional & 1,2 & 13 & $100 \%$ & 0 \\
\hline 18 & $58 /$ male & 1 & $\mathrm{ICH}$ & IV & regional & 2 & 48 & $100 \%$ & 1 \\
\hline 19 & $62 /$ male & 1,2 & $\mathrm{ICH}$ & IV & regional & 2 & 2 & $100 \%$ & 1 \\
\hline 20 & 70/male & 2,4 & $\mathrm{ICH}$ & IV & regional & 2 & 4 & $100 \%$ & 0 \\
\hline 21 & $68 /$ male & $1,2,4$ & $\mathrm{ICH}$ & IV & regional & 2 & 9 & $90 \%$ & 0 \\
\hline 22 & 70/female & 2,4 & $\mathrm{ICH}$ & IV & regional & 1 & 10 & $100 \%$ & 1 \\
\hline 23 & 57/female & $1,3,5$ & $\mathrm{ICH}$ & Ilb & extensive & 2 & 17 & $100 \%$ & 0 \\
\hline 24 & $68 /$ female & 1 & SAH & $\mathrm{Ilb}$ & regional & 2 & 3 & $100 \%$ & 2 \\
\hline 25 & $68 /$ male & 1,2 & $\mathrm{ICH}$ & IV & regional & 2 & 1 & $70 \%$ & 0 \\
\hline 26 & 48/female & 3 & $\mathrm{ICH}$ & Illb & extensive & 2 & 1 & $100 \%$ & 0 \\
\hline 27 & $31 /$ male & 1 & $\mathrm{ICH}$ & Ilb & regional & 2 & 73 & $100 \%$ & 1 \\
\hline 28 & 66/female & 3 & $\mathrm{ICH}$ & Ila & extensive & 2 & 8 & $100 \%$ & 0 \\
\hline 29 & 49/male & $2,3,4$ & $\mathrm{ICH}$ & IV & regional & 2 & 6 & $80 \%$ & 2 \\
\hline 30 & $60 /$ male & 4 & $\mathrm{ICH}$ & IV & regional & 2 & 14 & $100 \%$ & 1 \\
\hline
\end{tabular}

* 1: Headache; 2: Deterioration of consciousness/coma; 3: Focal neurologic deficit; 4: Seizure; 5: Dementia

**From reference 16. Regional (engorged medullary veins involved only one cerebral or cerebellar hemisphere); extensive (engorged medullary veins involved more than one cerebral hemisphere or both the cerebrum and cerebellum)

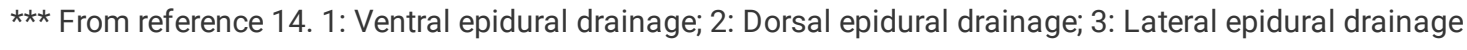

SAH; subarachnoid hemorrhage, ICH; intracerebral hematoma, SDH; subdural hematoma, 


\begin{tabular}{|c|c|c|c|c|c|c|c|c|c|}
\hline & Age/sex & Symptoms/signs* & $\begin{array}{l}\text { Type of } \\
\text { hemorrhage }\end{array}$ & $\begin{array}{l}\text { Cognard } \\
\text { classification }\end{array}$ & $\begin{array}{l}\text { Engorged } \\
\text { medullary } \\
\text { veins ** }\end{array}$ & $\begin{array}{l}\text { Drainage } \\
\text { location*** }\end{array}$ & $\begin{array}{l}\text { Days } \\
\text { between } \\
\text { hemorrhage } \\
\text { and } \\
\text { treatment }\end{array}$ & $\begin{array}{l}\text { Obliteration } \\
\text { percentage }\end{array}$ & $\begin{array}{l}\text { mRS } \\
\text { in last } \\
\text { follow } \\
\text { up }\end{array}$ \\
\hline 31 & 45/male & 1 & $\mathrm{ICH}$ & IV & regional & 2 & 6 & $100 \%$ & 0 \\
\hline 32 & $58 /$ male & 1 & $\mathrm{ICH}$ & IV & regional & 2 & 4 & $100 \%$ & 0 \\
\hline \multicolumn{10}{|c|}{ * 1: Headache; 2: Deterioration of consciousness/coma; 3: Focal neurologic deficit; 4: Seizure; 5: Dementia } \\
\hline \multicolumn{10}{|c|}{$\begin{array}{l}\text { **From reference } 16 \text {. Regional (engorged medullary veins involved only one cerebral or cerebellar hemisphere); extensive (engorged } \\
\text { medullary veins involved more than one cerebral hemisphere or both the cerebrum and cerebellum) }\end{array}$} \\
\hline \multicolumn{10}{|c|}{ 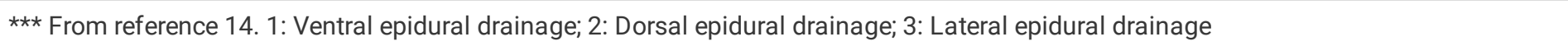 } \\
\hline \multicolumn{10}{|c|}{ SAH; subarachnoid hemorrhage, ICH; intracerebral hematoma, SDH; subdural hematoma, } \\
\hline
\end{tabular}

\section{Discussion}

In this study, hemorrhage is found in $11.3 \%$ of DAVFs. They are more commonly found in cases with EMVs, especially regional types. In $75 \%$ of the hemorrhagic DAVFs have dorsal epidural drainage on an embryonic anatomic basis. There was no significant difference in mRS after treatment between the groups above or below 65 years old. Patients who received treatment within 14 days were associated with better outcomes than the group exceeding 14 days.

In addition to Cognard classification, EMVs and regional type EMVs had been reported to be risk factors of aggressive symptoms and hemorrhage in DAVFs $[9,13]$. There were 27 cases $(84.4 \%)$ which presented EMVs in our patients of hemorrhagic DAVFs, and 26 of them (81.5\%) were regional-type lesions. The result might reveal high relevance of EMVs and regional type EMVs to hemorrhages in DAVFs. CVR can be found in many asymptomatic patients of DAVF [11]. Three major cerebral superficial veins are superficial middle sylvian vein, vein of Trolard, and vein of Labbe. They consist of the anastomotic channels between the superior sagittal sinus and transverse sinus. In many asymptomatic DAVFs with CVR, the CVR serves as superficial cortical venous collateral circulation. The cerebral deep venous system mainly consists of internal cerebral and basal veins. They converge to form the vein of Galen and drain into the straight sinus and then to the torcular, which is the confluence of bilateral transverse sinuses. In patients with DAVFs, if the CVR through the superficial anastomotic veins are occluded or deficient, the connection between cortical veins, subcortical veins, and medullary veins are the main collateral to the deep venous system. This causes the EMVs. We suppose such deep collateral in patients with extensive type EMV is abundant, and those with regional type are not. Such inadequate deep drainage might cause venous hypertension and eventually result in bleeding.

Geibprasert S. et al. proposed a new classification of DAVFs according to three groups of drainage locations [13], and they found lateral and dorsal epidural spaces were statistically related to aggressive symptoms. In our study, $75 \%$ had solely dorsal epidural drainage and we consider this drainage location is highly related to hemorrhage in DAVFs. We proposed that regional type EMVs, dorsal epidural drainage are additional risk factors of hemorrhage in DAVFs.

The average case fatality after DAVF-related hemorrhage was $4.7 \%$ in systematic literature research [14]. Less deep hemorrhages [15]and venous rather than arterial bleeding sites [16] have been speculated to explain better outcomes in hemorrhagic DAVFs. In our case review, there was no fatality after the treatments or during the period of follow-up. In our series, a poor outcome (mRS $\geq 3$ ) after treatment was 15.6\% (5/32), higher than the reported $8.3 \%$ [14]. However, four in these five received treatments more than 14 days after diagnosis, and we supposed this was the major factor of poor outcome.

Several limitations of our study are noted in this study. First, this study is a retrospective study with a moderate number of cases. Hemorrhagic DAVF is uncommon and occasionally treated as an emergent condition; therefore, it is difficult to have a prospective study. In this study, the treatment is variable in different eras, and this might be one of the factors that influence the outcome. However, there is still a lack of reports about the status quo of outcome after treatment in hemorrhagic DAVFs.

In conclusion, regional EMV and dorsal epidural drainage patterns are risk factors in the prediction of hemorrhage in intracranial DAVFs. Aging and gender are not a factor influencing clinical outcome after endovascular treatment. Patients who received early treatment within 14 days after hemorrhage could have a better clinical outcome.

\section{Methods}




\section{Patients and clinical data}

The present study was approved by the National Taiwan University Hospital ethics committee/institutional review board and was exempted from informed consent requirements owing to its retrospective design. All methods in this research were performed in accordance with the relevant guidelines and regulations including the Declaration of Helsinki. We searched our neurointerventional surgery datasheet from 1 December 1996 to 30 April 2015. Patients diagnosed with intracranial DAVF by catheter angiography and who received endovascular treatment were included in the study. We recorded the clinical data and images of these patients, collected age, sex, onset symptoms, Cognard classification, presentation of EMVs or not, drainage location, types of hemorrhage, approaching method, embolization media, embolization percentage, mRS after treatments (Table 1). All hemorrhages were confirmed by CT or MR images. An EMV is extensive when it involves more than one cerebral hemisphere or both the cerebrum and cerebellum, and it is regional when it involves only one cerebral or cerebellar hemisphere [9]. Besides Cognard classification, we also analyzed the cases with classification from Geibprasert et al [13]. They propose a classification of DAVFs by the evolution and embryological development of venous-sinus drainage of the central nervous system [13]. They classified the drainage into three compartments: ventral, dorsal, and lateral groups. The ventral group includes basioccipital bone, the petrous pyramid, the basisphenoid with its adjacent sphenoid wings, and their related dural structures. The dorsal group includes superior sagittal sinus, torcular, transverse sinus, medial occipital sinus, and posterior marginal sinus. The lateral group includes emissary-bridging veins of the brainstem and their homologs draining deep brain structures such as the condyloid vein at the foramen magnum, the superior petrosal vein, the basal vein, the vein of Galen, the veins of the anterior cranial fossa, and the orbit. We defined a poor outcome as an mRS $\geq 3$. After the final treatment, the patient would receive clinical follow-up and MR imaging studies at 3rd, 6th, 12th, and 24th months if possible. Time-offlight and contrast-enhanced MR angiography were part of the routine follow-up MR imaging examination. After the 24-month follow-up, if the patient presented with complete obliteration or without significant clinical symptoms, the follow-up is on a voluntary basis.

\section{Statistical analysis}

We used R software, version 3.5.1 for windows, to analyze the data. Mean age, proportions of males and females, mean days from diagnosis to treatment, mean duration of follow-up, proportions of the positions of lesions and hemorrhage, and proportion of patients who had poor outcomes were calculated. We used Student's t-test to evaluate the mRS after treatments between the groups: male and female; $<65$ and $\geq 65$ years old; $<7$ days, 7 to 14 days, and $>14$ days from diagnosis to treatment.

\section{Declarations}

\section{Funding}

The authors received no financial support for the research, authorship, and/or publication of this article.

\section{Authors' contributions}

Chih-Cheng Wan and Hon-Man Liu wrote the main manuscript text.

Hon-Man Liu prepared figures 1-2.

Chih-Cheng Wan prepared table 1.

All authors reviewed the manuscript.

\section{Declaration of conflicting interest}

The authors declared no potential conflicts of interest with respect to the research, authorship, and/or publication of this article.

\section{References}

1. Davies MA, TerBrugge K, Willinsky R, Coyne T, Saleh J, Wallace MC. The validity of classification for the clinical presentation of intracranial dural arteriovenous fistulas. J Neurosurg. 1996 Nov;85(5):830-7. doi: 10.3171/jns. 1996.85.5.0830.

2. Al-Shahi R, Bhattacharya JJ, Currie DG, Papanastassiou V, Ritchie V, Roberts RC, Sellar RJ, Warlow CP; Scottish Intracranial Vascular Malformation Study Collaborators. Scottish Intracranial Vascular Malformation Study (SIVMS): evaluation of methods, ICD-10 coding, and potential sources of bias in a prospective, population-based cohort. Stroke. 2003 May;34(5):1156-62. doi:

10.1161/01.STR.0000069012.23858.69.

3. Cognard C, Gobin YP, Pierot L, Bailly AL, Houdart E, Casasco A, Chiras J, Merland JJ. Cerebral dural arteriovenous fistulas: clinical and angiographic correlation with a revised classification of venous drainage. Radiology. 1995 Mar;194(3):671-80. doi:

Page 6/9 
10.1148/radiology.194.3.7862961.

4. Sarma D, Ter Brugge K. Management of intracranial dural arteriovenous shunts in adults. Eur J Radiol. 2003 Jun;46(3):206-20. doi: 10.1016/s0720-048x(03)00092-5.

5. Borden JA, Wu JK, Shucart WA. A proposed classification for spinal and cranial dural arteriovenous fistulous malformations and implications for treatment. J Neurosurg. 1995 Feb;82(2):166-79. doi: 10.3171/jns. 1995.82.2.0166.

6. Duffau H, Lopes M, Janosevic V, Sichez JP, Faillot T, Capelle L, Ismaïl M, Bitar A, Arthuis F, Fohanno D. Early rebleeding from intracranial dural arteriovenous fistulas: report of 20 cases and review of the literature. J Neurosurg. 1999 Jan;90(1):78-84. doi: 10.3171/jns. 1999.90.1.0078.

7. van Dijk JMC, Ter Brugge KG, Willinsky RA, Wallace MC. Clinical course of cranial dural arteriovenous fistulas with long-term persistent cortical venous reflux. Stroke. 2002 May;33(5):1233-6. doi: 10.1161/01.str.0000014772.02908.44.

8. Lin YH, Wang YF, Liu HM, Lee CW, Chen YF, Hsieh HJ. Diagnostic accuracy of CTA and MRI/MRA in the evaluation of the cortical venous reflux in the intracranial dural arteriovenous fistula DAVF. Neuroradiology. 2018 Jan;60(1):7-15. doi: 10.1007/s00234-017-1948-2.

9. Lin YH, Lee CW, Wang YF, Lu CJ, Chen YF, Liu HM. Engorged medullary vein on CT angiography in patients with dural arteriovenous fistula: prevalence, types, and comparison between regional and extensive types. J Neurointerv Surg. 2018 Nov;10(11):1114-9. doi: 10.1136/neurintsurg-2017-013660.

10. Söderman M, Pavic L, Edner G, Holmin S, Andersson T. Natural history of dural arteriovenous shunts. Stroke. 2008 Jun;39(6):1735-9. doi: 10.1161/STROKEAHA.107.506485.

11. Strom RG, Botros JA, Refai D, Moran CJ, Cross DT 3rd, Chicoine MR, Grubb RL Jr, Rich KM, Dacey RG Jr, Derdeyn CP, Zipfel GJ. Cranial dural arteriovenous fistulae: asymptomatic cortical venous drainage portends less aggressive clinical course. Neurosurgery. 2009 Feb;64(2):241-7; discussion 247-8. doi: 10.1227/01.NEU.0000338066.30665.B2.

12. Zhao LB, Suh DC, Lee DG, Kim SJ, Kim JK, Han S, Lee DH, Kim JS. Association of pial venous reflux with hemorrhage or edema in dural arteriovenous fistula. Neurology. 2014 May 27;82(21):1897-904. doi: 10.1212/WNL.0000000000000448.

13. Geibprasert S, Pereira V, Krings T, Jiarakongmun P, Toulgoat F, Pongpech S, Lasjaunias P. Dural arteriovenous shunts: a new classification of craniospinal epidural venous anatomical bases and clinical correlations. Stroke. 2008 Oct;39(10):2783-94. doi: 10.1161/STROKEAHA.108.516757.

14. Jolink WM, van Dijk JM, van Asch CJ, de Kort GA, Algra A, Groen RJ, Rinkel GJ, Klijn CJ. Outcome after intracranial haemorrhage from dural arteriovenous fistulae; a systematic review and case-series. J Neurol. 2015 Dec;262(12):2678-83. doi: 10.1007/s00415-015-7898-X.

15. Cordonnier C, Al-Shahi Salman R, Bhattacharya JJ, Counsell CE, Papanastassiou V, Ritchie V, Roberts RC, Sellar RJ, Warlow C; SIVMS Collaborators. Differences between intracranial vascular malformation types in the characteristics of their presenting haemorrhages: prospective, population-based study. J Neurol Neurosurg Psychiatry. 2008 Jan;79(1):47-51. doi: 10.1136/jnnp.2006.113753.

16. Daniels DJ, Vellimana A K, Zipfel GJ, Lanzino G. Intracranial hemorrhage from dural arteriovenous fistulas: clinical features and outcome. Neurosurg Focus. 2013 May;34(5):E15. doi: 10.3171/2013.4.FOCUS1335.

\section{Figures}




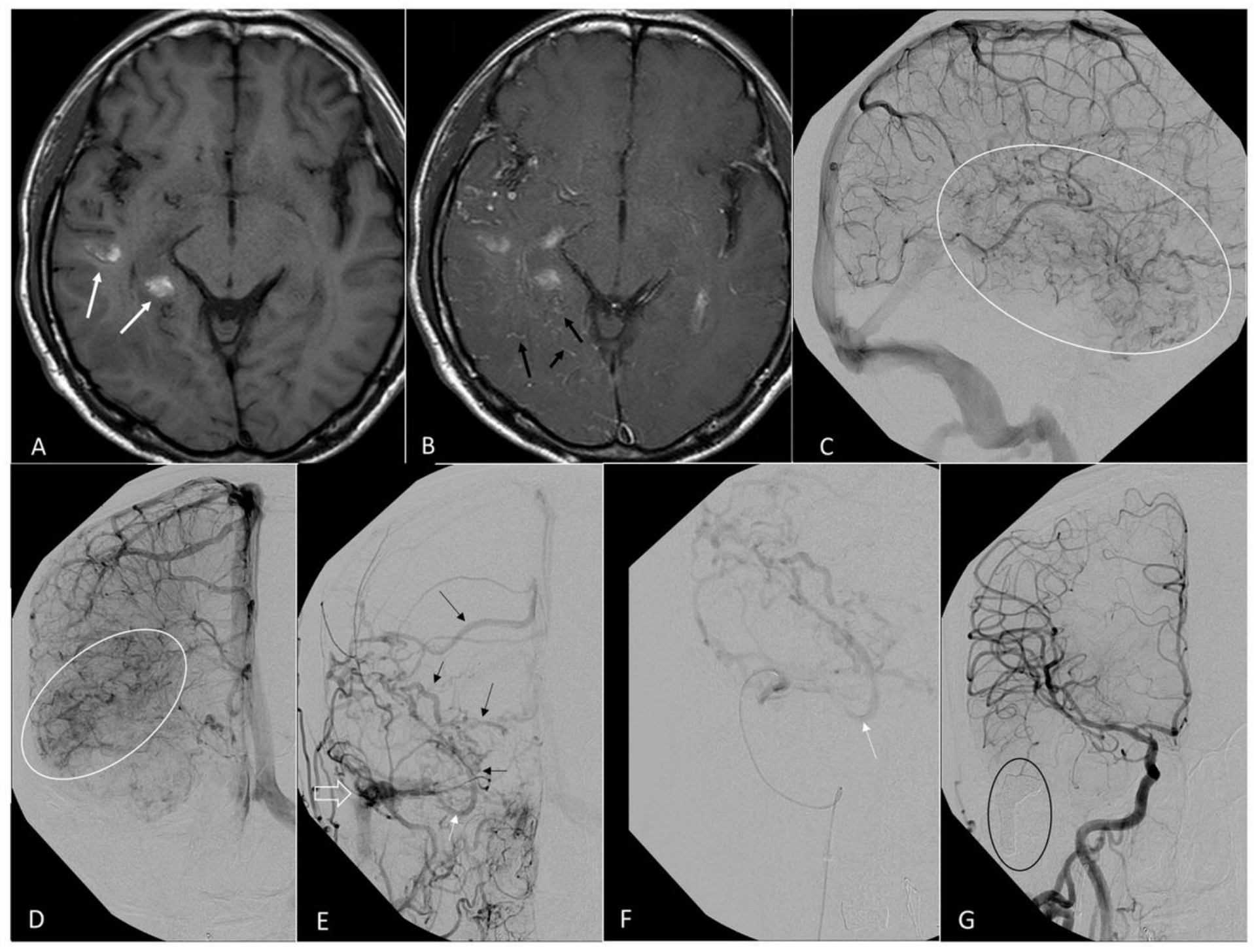

Figure 1

A 59 years male patient had a sudden onset of loss of consciousness and seizure attack 1 week ago. T1-weighted image (A) shows hematomas (white arrows) in the right temporal lobe. Contrast enhanced T1-weighted image(B) depicts regional multiple engorged medullary veins (black arrows) in the right temporal lobe and occipital lobe. Catheter angiography of the right internal carotid artery (lateral view; $\mathrm{C}$, $\mathrm{AP}$ view; D)) shows congestion of the medullary veins in the right temporal lobe (white circle). The external carotid artery angiography (frontal view; E) shows a dural arteriovenous fistula (large white arrow) in the right transverse sinus with cortical reflux into the middle cerebral vein (small white arrow), and then into multiple dilated medullary veins (black arrows). Through the occluded sigmoid sinus, the microcatheter is navigated at the fistula site microangiography (F) with confirmation of the reflux to the middle cerebral vein (white arrow). Multiple detachable coils (black circle) were deployed and packed in the isolated sinus and resulted in complete occlusion of the fistula (G). 


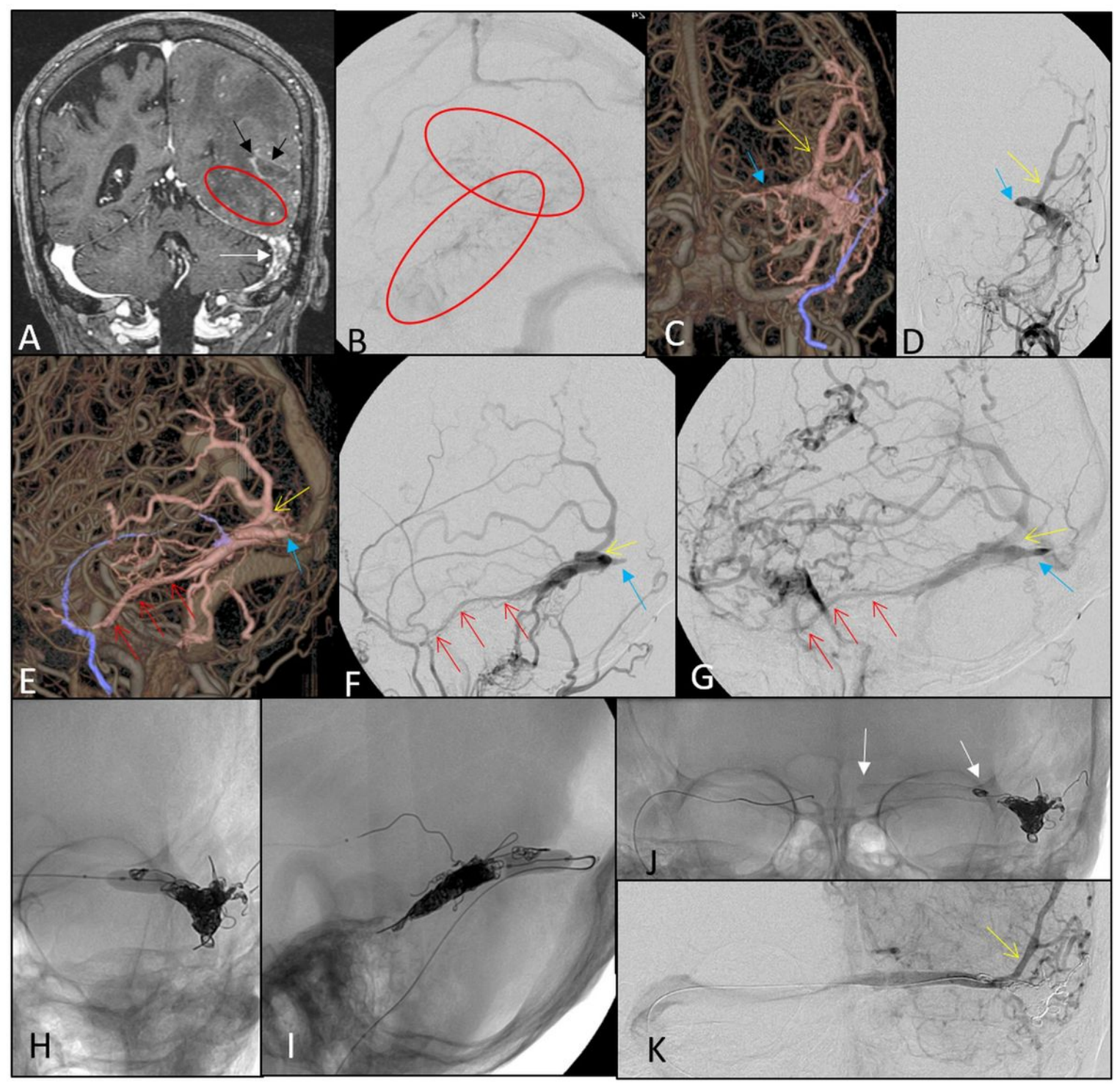

\section{Figure 2}

An 81 years old female patient had progressive dementia for 4 years, aphasia and right hemianopia for 2 months. Post-contrast T1-weighted image ( $\mathrm{A}$; coronal) shows diffuse brain edema in left cerebral hemisphere, chronic hematoma in left temporal lobe (black arrows), and multiple regional engorged medullary veins (red circle) as enhanced dots in white matter. Thrombosis is shown in the left sigmoid sinus (white arrow). Venous phase of left internal carotid artery angiography (B) depicts dilated and engorged medullary veins (red circle) in temporo-parietal lobes. Reconstructive CT angiography (C; frontal, E; lateral), early arterial phase (D; frontal, F; lateral) and late arterial phase (G; lateral) of left external carotid angiography show isolated sinus dural arteriovenous fistula at the mid-transverse sinus just distal to the junction of vein of Labbe (yellow arrow) with cortical venous reflux. Cortical venous reflux is also noted to the superior petrous sinus (red arrows). The connection between transverse sinus and torcula is occluded (blue arrow). No direct communication between the vein of Labbe to the vein of Trodard or superficial middle cerebral vein. Multiple small, tortuous but dilated anastomotic veins are shown. Contralateral transvenous approach through the occluded left transverse sinus combining with trans-arterial (middle meningeal artery) coiling are performed. The fistula site is completely occluded with multiple detachable coils under balloon protection at the junction of vein of Labbe ( $\mathrm{H}$; frontal, l; lateral). Finally, a stent (white arrows) is deployed at the proximal transverse sinus (J) to increase the outflow. The vein of Labbe (K; yellow arrow) is patent and associated with normal drainage flow direction to the transverse sinus. The patient had a mRS of 1 in a 2-year follow up without evidence of re-bleeding. 